\title{
ASSOCIATION OF INFANT FEEDING PRACTICES AND FOOD NEOPHOBIA AMONG PRE-SCHOOL CHILDREN IN OROGUN COMMUNITY, IBADAN
}

\author{
${ }^{* 1}$ Okonkwo, E. M. \& ${ }^{2}$ Samuel, F. O.
}

\begin{abstract}
${ }^{*}{ }^{1}$ Department of Human Nutrition and Dietetics, Michael Okpara University of Agriculture Umudike, Umudike Abia State Nigeria ${ }^{2}$ Department of Human Nutrition, College of Medicine, University of Ibadan, Ibadan, Oyo State Nigeria

*Corresponding author Email: elizabethokonkwo43@gmail.com Phone: +2348061529484
\end{abstract}

\begin{abstract}
This study determined food neophobia (FN) and the relationship of infant feeding practice (IFP) and (FN) among pre-school children in Orogun community, Ibadan. Three hundred and seventy mothers of pre-school children were selected using a systematic random sampling technique from a pre-survey house to house list of eligible children. A semi-structured questionnaire that included socio-demographic characteristics, retrospective breastfeeding practice, retrospective complementary feeding practice (CFP) and FN scales were used to collect information. Data were analyzed using descriptive and logistic regression. The exclusive breastfeeding (EBF) rate was $26.8 \%$ and $38 \%$ of the mothers had a good breastfeeding practice. Timely initiation of complementary feeding was 54\%. The prevalence of FN was 35\%. Logistic regression analysis showed that the odds for FN was higher among children who were initiated to breastfeeding late $(\mathrm{OR}=1.45$, 95\% CI: $0.886-2.31)$, children that were not breastfed on demand ( $\mathrm{OR}=1.766,95 \%$ CI: $0.925-3.372)$, those not exclusively breastfed for six months $(\mathrm{OR}=1.366,95 \% \mathrm{CI}$ : $0.834-2.240)$ and children introduced to complementary food before 6 months $(\mathrm{OR}=1.473,95 \%$ CI: $0.787-2.760)$. Most rejected foods were from the fruits and vegetable group. There were suboptimal IFP in the study and prevalence of FN was high. Poor IFP were associated with FN. Community-based nutrition education programs should be encouraged to improve IFP.
\end{abstract}

Keywords: breastfeeding, complementary feeding, breast milk, exclusive breastfeeding, food neophobia, infant feeding practice.

LICENSE: This work by Open Journals Nigeria is licensed and published under the Creative Commons Attribution License 4.0 International License, which permits unrestricted use, distribution, and reproduction in any medium, provided this article is duly cited.

COPYRIGHT: The Author(s) completely retain the copyright of this published article.

OPEN ACCESS: The Author(s) approves that this article remains permanently online in the open access (OA) model.

QA: This Article is published in line with "COPE (Committee on Publication Ethics) and PIE (Publication Integrity \& Ethics)". 


\section{INTRODUCTION}

Infant feeding recommendations (WHO 2018) such as exclusive breastfeeding (EBF) for six months, timely and adequate complementary feeding practices (CFP) and continued breastfeeding until a child is 24 months are important for normal physical growth and development. Adherence to recommended infant feeding practices (IFP) is not only associated with positive health outcomes among infants but also linked to desirable eating behaviour in the second year of life and beyond (Shim et al., 2011). IFP employed by mothers may determine how well a child accepts family foods, this stems from the fact that infants can learn about the flavour of foods from breast milk before the first taste of food ((Mennella, 2007). Even with these many benefits of breastfeeding, substandard breastfeeding practices (BP), inadequate and inappropriate CF has been reported (Kelechi-Ebisike et al., 2020).

The second year of life marks a transition from the consumption of breast milk and complementary food to family foods. At this stage nutrients' needs increase, accompanied by developmental changes as this group of children seek independence at mealtime and are easily distracted during feeding (Benjasuwantep, et al., 2013). Aligning with these are the difficulties of accepting a variety of new foods with different tastes, textures, and colours and putting them at risk of feeding problems (Birch and Doub, 2014). The most documented feeding problems in the literature among this group include picky eating, limited intake of food and food neophobia (FN) (Kutbi 2020, Samuel and Ugochukwu 2016, Shim et al., 2011).

FN has been described as the reluctance of eating or avoidance of new foods in early childhood (Pliner and Hobden 1992, Pliner 1994). FN is lesser in infancy, rises rapidly around the age of two, and gradually decreases thereafter (Dovey 2008). FN may be established by several factors such as; maternal feeding practice (Kutbi, 2020), parental feeding methods (Birch et al., 2003), IFP, including when parents decide to introduce solids (Shim et al., 2011), exposure and variety of foods (Birch et al., 1998).

Heightened FN can affect children's dietary intake, adequacy and quality (Howard et al., 2012). IFP employed have been proposed to predict dietary patterns at age two and beyond (Kutbi, 2020) and limited studies have reported the interrelation between IFP and feeding problems such as FN in this region. The study aimed to determine FN, find the association between past IFP and FN. Document new foods rejected by food neophobic in a sample of pre-school children living in Orogun community, Ibadan.

\section{MATERIALS AND METHODS}

The study was a descriptive cross-sectional study conducted between April and July 2017 in Orogun Community. It is one of the few urban communities in Akinyele Local Government, Ibadan, Oyo State. It is a medium residential area, it houses urban slums, several estates and gated residential areas. Orogun community was selected for this study as a result of the demographic diversity of the population.

\section{SAMPLING PROCEDURE}

Sample size was determined using Fischer's sample size formula, $(N)=\frac{w^{2}}{d^{2}} X p$ X q. N= Minimum sample size, w $=$ standard normal deviate corresponding to $95 \%$ confidence interval; proportion of an indicator measured (prevalence of FN); $\mathrm{q}=1-\mathrm{p} ; \mathrm{d}=$ desired precision (0.05). Taking prevalence of FN as 39\% (Samuel and Ugochukwu 2016), where 
$\mathrm{w}=1.96$ (constant), $\mathrm{d}=0.05, \mathrm{p}=39 \%, \mathrm{q}=1-\mathrm{p}(39 \%)$. Sample size $(\mathrm{N})$ was 366 and was approximated to $370 . \mathrm{A}$ three-stage sampling procedure was applied in selecting the mothers. At first, Akinleye LGA was purposively selected. A random sampling of Orogun community and a pre-survey house-to-house visit was done to get the list of eligible children. At the third stage, systematic sampling technique was used to select 370 consenting mothers of children 2436 months.

\section{RESEARCH INSTRUMENT}

A pre-tested semi-structured questionnaire consisting of closed and open-ended questions was employed to elicit responses from the study participants which included socio-demographic characteristics, retrospective BP, retrospective $\mathrm{CF}$ practice and $\mathrm{FN}$.

\section{RETROSPECTIVE BP}

Information on retrospective BP was determined by asking questions using some key BP indicators as recommended by WHO/UNICEF (WHO/UNICEF, 2018). The following are the seven items: Timely initiation of breastfeeding (< 1 or $>1$ hour), any pre-lacteal feeding, colostrum feeding, bottle feeding, any liquid given (except medicine), formula given and any solid or semi-solid given from birth to 6 months of life. All inappropriate BP were scored zero while recommended BP were scored as 1. This was used to generate a seven-point score. The summed score was divided into two categories; scores of 0 - 4 as poor BP and scores of 5 - 7 as good BP.

\section{RETROSPECTIVE CF PRACTICE}

Retrospective CF practice was constructed in line with the current CF recommendations (UNICEF, WHO, 2018). This includes: Timely initiation of CF, continued breastfeeding, meal frequency in a day, Food frequency and continued breastfeeding. Food consumption in the past was obtained using the food frequency questionnaire (Mejía-Rodríguez et al., 2014). The food groups were seven with 27 items and each food group was scored individually.

\section{DETERMINATION OF CHILDREN'S FOOD NEOPHOBIA}

The Child Food Neophobia Scale (CFNS) (Pliner \& Hobden, 1992) is a validated 10 item tool that uses mothers reporting of child neophobia. But in this research, a six-item of CFNS commonly used for young children was adapted: "My child does not like new foods", "If my child does not know what is in a food he/she will not try it", "My child is afraid to eat things he/she has never had before", "My child is very particular about the food he/she will eat", "My child will eat almost everything(reverse score)", "My child is constantly sampling new and different foods (reverse score)" (Pliner \& Hobden, 1994). Mothers completed the CFNS by rating their children's eating behaviours on a Likert scale of 1 (Disagree Strongly) to 4 (Agree strongly), where the total minimum score obtainable is 6 and the maximum score of 24 which indicate higher FN.

CFNS scores can be classified by showing the grade of FN. The respondents were grouped into three by the $33^{\text {rd }}$ and $60^{\text {th }}$ percentile as cut-off points. Those who scored 6-12 as food neophilics, scores 13-17 as average and scores 18-24 were grouped as food neophobic (Falciglia et al., 2000) Foods rejected by food neophobic children were 
obtained in an open-ended question asking mothers to list the new foods that the child has rejected and this was reported in food groups.

\section{DATA ANALYSIS METHOD}

Statistical interpretation of data collected was computed using SPSS (version 22). Categorical data were presented using frequency (and percentages), but continuous data were summarized using mean \pm standard deviation (SD). Logistic regression analysis was conducted to examine associations between child FN and IFP. FN was expressed as a dichotomous variable with category 1 for food Neophilia and 0 for FN. This variable was examined against some key infant feeding indicators.

\section{ETHICAL APPROVAL}

The Institution Review Board of the University of Ibadan/University College Hospital (UI/UCH) ethics committee approved the study (UI/EC/17/0194). All respondents gave verbal informed consent before participation

\section{RESULTS AND DISCUSSION}

Table 1 shows the socio-demographic data of the mothers and children. The mean age of surveyed children was 30.2 \pm 4.2 months and mean age of mothers was $31.9 \pm 5.86$ years. Majority $(87 \%)$ had secondary school education and tertiary education. The majority of mothers were employed.

Table 1: Socio-demographic characteristics of the study population

\begin{tabular}{ll}
\hline Variables & $\%$ \\
\hline $\begin{array}{l}\text { Mothers' Characteristics } \\
\text { Mean age (in years) } \pm \text { standard deviation }\end{array}$ & $31.9 \pm 5.86$ \\
Education level & \\
$\leq$ Secondary education & 87.1 \\
& \\
Employment status & \\
Unemployed & 78.9 \\
Employed & 78.9 \\
No of children & \\
One child & 21.9 \\
Two children & 34.1 \\
Z3 children & 44.0 \\
Child's characteristics & \\
Age (in months), mean \pm standard deviation & $30.2 \pm 4.2$ \\
Sex & \\
Females & 50.3 \\
Males & 49.7 \\
\hline
\end{tabular}


Table 2: Mothers' retrospective account of breastfeeding pattern

\begin{tabular}{ll}
\hline Indicator & Frequency (\%) \\
\hline Breastfeeding initiation & \\
Within 1 hour & 46.2 \\
After 1 hour & 53.8 \\
Colostrum feeding & 79.2 \\
Yes & 20.8 \\
No & \\
Pre-lacteal feed & 37.3 \\
Not Given & 62.3 \\
Given & \\
Interval of breastfeeding & 80 \\
On-demand & 20 \\
As convenient for mothers & \\
Liquid /formula given during the first 6 & \\
Months & 73.2 \\
Given & 26.8 \\
Not given & \\
Feeding bottle use & 46.8 \\
Yes & 53.2 \\
No & \\
Solid or semi-solid given in the first 6 months & 32.2 \\
Yes & 63.8 \\
No & \\
Mothers' level of BP & 62 \\
Poor Practice & 38 \\
Good Practice &
\end{tabular}

Table two shows mothers' retrospective accounts of BP. Findings from this study show that $38 \%$ of mothers had a good BP. This observation was less than the result of a study in Abuja Nigeria (Omuemu and Adamu 2018) and in contrast, slightly higher than that of Sanusi et al (2016) who reported 22\% for good BP. Timely initiation of breastfeeding immediately after birth is necessary for profitable lactation. It was ascertained that the timing of breastfeeding initiation was not optimal as only half (54\%) of mothers put their babies to the breast within the first one hour after delivery. Contrary to this, a higher percentage (74\%) of breastfeeding initiation in the first one hour was reported (Kelchi-ebisike et al., 2020) while a much lower percentage was reported in another study (Atimati and Adam 2020). Pre-lacteal feeding was noted to be high; more than half (63\%) of infants received a pre-lacteal feed. This aligns with other studies (Atimati and Adam 2020, Pareek 2019). The habit of pre-lacteal feeding is not recommended because it delays breastfeeding initiation, hampers suckling and is the main constraint to EBF. Contrary to WHO recommendations, early commencement of liquid or formula before the six months was noted in $73 \%$ of the research population. Therefore in this study, EBF rate was $26.8 \%$, this rate was slightly lower than the current EBF rate in Nigeria which is $29 \%$ it still did not meet the national goal of 50\%. Higher prevalence of EBF has been reported in recent studies (Kelechi-Ebisike et al., 2020, Manyeh et al., 2020). Increased rates of EBF in these studies may be due to wider awareness of the many benefits of EBF. 
Table 3: Mothers' retrospective report of complementary feeding practice

\begin{tabular}{|c|c|}
\hline Indicator & Percentage \\
\hline \multicolumn{2}{|l|}{ Initiation of $\mathbf{C F}$} \\
\hline Too early initiation & 32.2 \\
\hline Timely initiation & 54.1 \\
\hline Late initiation & 13.8 \\
\hline \multicolumn{2}{|l|}{ Continued breastfeeding } \\
\hline Yes & 95.1 \\
\hline No & 4.9 \\
\hline \multicolumn{2}{|l|}{ Meal frequency in a day } \\
\hline $0-2$ times & 16.5 \\
\hline 3 times & 27.8 \\
\hline 4 times & 39.2 \\
\hline$\geq 5$ times & 16.5 \\
\hline \multicolumn{2}{|l|}{$\overline{\text { Food group consumed in a day }}$} \\
\hline $0-3$ food groups & 24.9 \\
\hline 4 food groups & 46.8 \\
\hline$\geq 5$ food groups & 28.4 \\
\hline \multicolumn{2}{|l|}{ Food frequency ( $\geq 1$ time in a week) } \\
\hline Milk and milk products & 73.8 \\
\hline Cereals & 94.8 \\
\hline Roots and tubers & 70 \\
\hline Legumes & 40 \\
\hline Meat and poultry & 14.9 \\
\hline Fish and fish products & 72.9 \\
\hline Vitamin A-rich fruits and vegetables & 35.9 \\
\hline \multicolumn{2}{|l|}{ Breastfeeding Cessation } \\
\hline Before first birthday & 7.6 \\
\hline Between $13-18$ months & 73.6 \\
\hline $19-23$ months & 11.9 \\
\hline Continue breastfeeding until second birthday and beyond & 7.0 \\
\hline \multicolumn{2}{|l|}{ Mean breastfeeding Duration } \\
\hline $18.2 \pm 5.78$ months & \\
\hline
\end{tabular}

Table three shows mothers' retrospective reports of CF practice, about half of the children commenced CF at six months. It was reported that mothers/caregivers do not follow the WHO recommendation for commencement of CF at six months (Udoh and Amodu, 2016). Similarly, only 54\% of infants were introduced to CF at six months this finding was consistent with a recent study (Sharma and Kafle 2020). Early initiation CF depicts poor nutrients consumption and could be the reason for the rate of feeding problems and under-nutrition in Nigeria among underfive children. Interestingly, almost all the mothers (95\%) continued breastfeeding after commencement of CF and only $7 \%$ of the mothers breastfed their children until 24 months. This low prevalence of mothers who continued breastfeeding until 24 months was consistent with that of Atimati and Adams (2020). Retrospective food consumption showed that starchy foods from cereals were the major (94\%) food group given to the studied children, a very few consumed foods from meats and vegetable groups. These results aligned with previously reported findings that the majority gave cereals while animal proteins, fruit and vegetable were the lowest food groups given (Forsido et al., 2019, Olatona et al., 2014). 


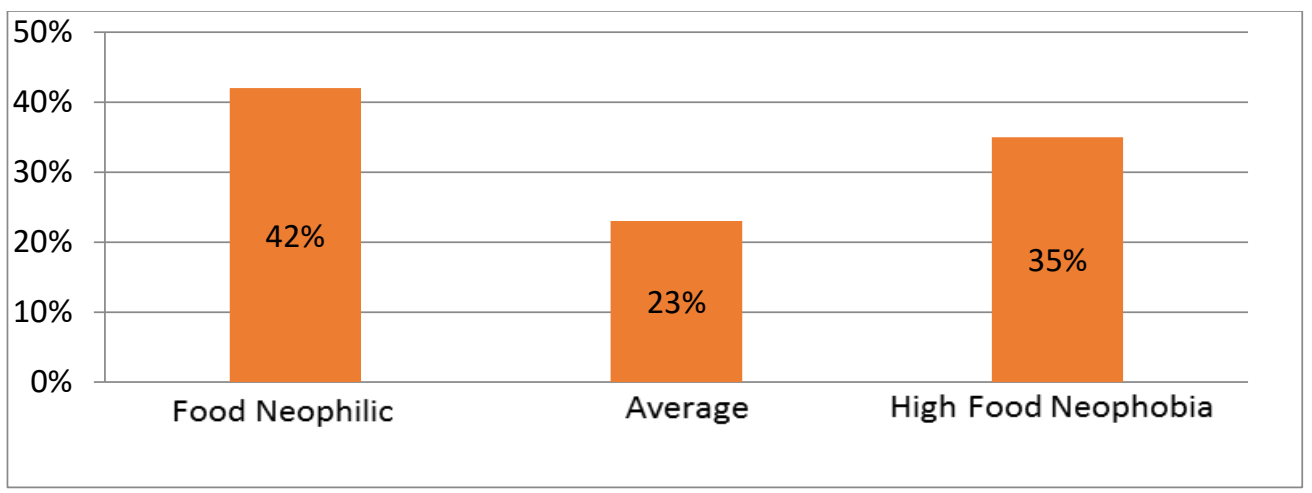

Figure 1: Prevalence of food neophobia

As shown in fig 1 the overall prevalence of FN among pre-school children studied was 35\%. A recent report shows a lower prevalence (Koziol-kozakowsha et al., 2018). These statistics, however, were slightly below the 39\% reported by Samuel et al (2016) and in contrast to a higher prevalence of 65\% reported by Shim et al (2011). The variation observed from this research may due to the differences in methods of measuring FN.

\section{LOGISTIC REGRESSION FOR ASSOCIATION OF IFP WITH FN}

The associations between IFP and FN were investigated as presented in table 4. Logistic regression analysis revealed a positive association between FN and breastfeeding initiation later than one hour after birth and breastfeeding on schedule. Higher odds for FN were observed among children not exclusively breastfed for six months $(\mathrm{OR}=1.366$, 95\% CI: 0.834- 2.240). This observation aligns with that of Shim et al (2011), children not exclusively breastfed throughout the first six months had a lower odd ratio for FN by $75 \%$. One explanation for this association is that dietary flavours are learned in utero since flavour can be transmitted through amniotic fluid and learning continues when infants are fed breast milk because mothers' dietary flavour can be transferred through breast milk (Mennella et al., 2001, Mennella 2007). Higher odds (OR = 1.473, 95\% CI: $0.787-2.760)$ for FN were observed among those that initiated CF late (after seven months) in comparison to those that were introduced at six months. Significant association between the commencement of CF and feeding problems later in life were reported in previous studies (Shim et al., 2011, Coulthard et al., 2009). The risk for FN was significantly higher among bottle-fed children and children not breastfed until 24 months.

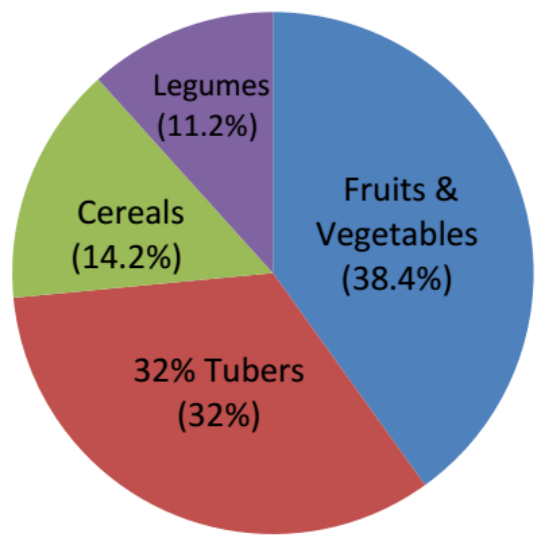

Figure 2: Food groups rejected by food Neophobic children $(\mathrm{n}=225)$ 
Table 4: Logistic Regression for Association of IFP with FN

\begin{tabular}{|c|c|c|}
\hline Indicators & Variables & Odd Ratio (95\% CI) \\
\hline \multicolumn{3}{|c|}{ Breastfeeding initiation } \\
\hline & In the first one hour & Reference \\
\hline & Later than first one hour & $1.455(0.886-2.891)$ \\
\hline \multicolumn{3}{|c|}{ Pre-lacteal feed } \\
\hline & No & Reference \\
\hline & Yes & $0.993(0.639-1.542)$ \\
\hline \multicolumn{3}{|c|}{ Colostrum given } \\
\hline & Yes & Reference \\
\hline & No & $0.981(0.580-1.660)$ \\
\hline \multicolumn{3}{|c|}{ Interval of breastfeeding } \\
\hline & On-demand & Reference \\
\hline & Every two hours & $1.283(0.598-2.750)$ \\
\hline & Every three hours & $1.766(0.925-3.372)$ \\
\hline \multicolumn{3}{|c|}{ Bottle feeding } \\
\hline & No & Reference \\
\hline & Yes & $1.314(0.857-2.014)$ \\
\hline \multicolumn{3}{|c|}{ Exclusive breastfeeding } \\
\hline & Yes & Reference \\
\hline & No & $1.366(0.834-2.240)$ \\
\hline \multicolumn{3}{|c|}{ Initiation of $\mathbf{C F}$} \\
\hline & Timely (at six months) & Reference \\
\hline & Early (before six months) & $1.020(0.633-1.646)$ \\
\hline & Late (after six months) & $1.473(0.787-2.760)$ \\
\hline \multicolumn{3}{|c|}{ Continue breastfeeding after six months } \\
\hline & Yes & Reference \\
\hline & No & $1.489(0.873-3.871)$ \\
\hline
\end{tabular}

Reference: response for those performing the recommended IFP

As shown in fig 2, mothers of neophobic children in this study reported that their children rejected at least one new food which was majorly from the vegetables and fruits group. This observation is in line with previous reports where vegetables and fruits were the most rejected food (Koziol-kozakowsha et al., 2018, Perry et al., 2015). It should be noted, however, that the least food group consume during CF were vegetables and fruits group and meat group. FN may prevent children from eating varieties of healthy diet (Howard et al., 2012). Repeated exposure is required for children of this age to accept novel foods.

\section{CONCLUSIONS}

The study shows that there are suboptimal infant IFP in the study area and prevalence of FN is high. It also found an association between IFP and FN. Early nutrition intervention programs should be planned and executed; this should include community-based approaches to promote adherence to recommended IFP. 
The study was not devoid of limitations, IFP were measured retrospectively and this depended on the mothers' memory to recall, though the validity and reliability of maternal recall for BF and CF practices have been documented ((Mejía-Rodríguez et al., 2014, Li et al., 2005). Future research should consider other factors that trigger FN apart from IFP.

\section{CONFLICT OF INTEREST}

There was no conflict of Interest.

\section{REFERENCES}

Atimati A.O \& Adam V.Y (2020) Breastfeeding practices among mothers of children aged 1-24 months in Egor Local Government Area of Edo State, Nigeria, South African Journal of Clinical Nutrition, 33:1, 10-16. Doi:10.1080/16070658.2018.1493071

Benjasuwantep B., Chaithirayanon S., \& Eiamudomkan M. (2013). Feeding problems in Healthy Young Children: Prevalence, related Factors and Feeding Practices. Pediatric Reports, 5(2), 38-4 DOIDOI: 10.4081\%2Fpr.2013.e10

Birch L.L, Doub A.E (2014) Learning to eat: birth to age 2. American Journal Clinical Nutrition; 99(3):723S-728S doi.10.3945/ajen.113.069047

Birch, L. L., Galloway, A. T., \& Lee, Y. (2003). Predictors and consequences of food neophobia and pickiness in young girls. Journal of American Dietitian Association 103(6):692-6, doi:10.1053/jada.2003.50134

Birch, L. L., Gunder, L., Grimm-Thomas, K., \& Laing, D. G. (1998). Infants' consumption of a new food enhances acceptance of similar foods. Appetite, 30(3), 283-295. doi:10.1006/appe.1997.0146

Coulthard H, Harris G, Emmett P. (2009). Delayed introduction of lumpy foods to children during the complementary feeding period affects child's food acceptance and feeding at 7 years of age. Maternal \& Child Nutrition. Jan; 5 (1):75-85 doi:10.1111/j.1740-8709.2008.00153.x.

Dovey T.M, Staples P.A, Gibson EL, Halford J.C. (2008). Food neophobia and 'picky/fussy eating in children: A review. Appetite.; 50(2-3):181-93. doi:10.1016/j.appet.2007.09.009.

Falciglia, G. A., Couch, S. C., Gribble, L. S., Pabst, S. M., \& Frank, R. (2000). Food neophobia in childhood affects dietary variety. Journal of American Diet Association 100(12):1474-81.DOI: 10.1016/S00028223(00)00412-0.

Forsido F.S, Kiyak N. Belachew T. and Hense O. (2019) Complementary feeding practices, dietary diversity, and nutrient composition of complementary foods of children 6-24 months old in Jimma Zone, Southwest Ethiopia Journal of Health, Population and Nutrition 3;38(1):14.DOI: 10.1186/s41043-019-0172-6.

Howard, A. J., Mallan, K. M., Byrne, R., Magarey, A., \& Daniels, L. A. (2012). Toddlers' food preferences; The impact of novel food exposure, maternal preferences and food neophobia. Appetite, 59(3):81825.doi:10.1016/j.appet.2012.08.022.

Kelechi-Ebisike V. O., Solomon M. D., Jaryum K. H., Ebisike K. J, Danjin M. (2020): “Prevalence of Early Initiation of Breastfeeding (EIBF) and Exclusive Breastfeeding (EBF) and Some Associated Factors among Mothers 
in Gombe Metropolis, Gombe State, Nigeria". Acta Scientific Nutritional Health 4.1 130-135doi: 10.31080/ASNH.2020.04.0586

Kozioł-Kozakowska A, Piórecka B, Schlegel-Zawadzka M. (2018) Prevalence of food neophobia in pre-school children from southern Poland and its association with eating habits, dietary intake and anthropometric parameters: a cross-sectional study. Public Health Nutrition. Apr;21 (6):1106-1114 DOI: $10.1017 / \mathrm{S} 1368980017003615$.

Kutbi H. A (2020) The Relationships between Maternal Feeding Practices and Food Neophobia and Picky Eating International journal of environmental research and public health.,(11)17,3894 doi:10.3390/ijerph17113894

Li R, Scanlon K.S \& Serdula M.K (2005) The validity and reliability of maternal recall of breastfeeding practice. Nutr Rev 63(4), 103-110.doi: 10.1111/j.1753-4887.2005.tb00128.x.

Manyeh A.K., Amu A., Akpakli D.E., JohnWilliams J.E, and Gyapong M (2020); Estimating the rate and determinants of exclusive breastfeeding practices among rural mothers in Southern Ghana International Breastfeeding Journal 15:7

Mejía-Rodríguez F., Neufeld L. M., García-Guerra A. Amado D. Quezada-Sanchez A. D., Orjuela M. A., (2014) Estimation of diet Validation of a food frequency questionnaire for retrospective during the first 2 years of life Maternal Child Health Journal. 18(1):268-285.doi: 10.1007/s10995-013-1263-4.

Mennella J.A, Jagnow C.P, Beauchamp G.K. (2001). Prenatal and Postnatal Flavor Learning by Human Infants. Pediatrics; 107(6):E88.doi: 10.1542/peds.107.6.e88.

Mennella J.A. (2007).The chemical senses and the development of flavour preferences in humans. In: Hartmann PE, Hale T, eds. Textbook on human lactation. Amarillo, TX: Hale Publishing: Pg 403-414.

Okafoagu N. C, Oche O. M., Raji M. O., Onankpa B., Raji I. (2017) Factors influencing complementary and weaning practices among women in rural communities of Sokoto state, The Pan African Medical Journal.; 28:254.doi: 10.11604/pamj.2017.28.254.10992.

Olatona F. A, Odozi M. A, Amu E. O.,(2014) Complementary Feeding Practices among Mothers of Children under Five Years of Age in Satellite Town, Lagos, Nigeria. Food and Public Health, 4(3): 93-98 doi:10.5923/j.fph.20140403.04

Omuemu V.O \& Adamu S.A Assessment of breastfeeding knowledge and practices among working mothers in the federal capital territory Nigeria International Journal Community Medicine and Public Health. 2019 Jan; 6(1):20-29 DOI:10.18203/2394-6040.ijcmph20185222

Pareek. S (2019) Exclusive breastfeeding in India: An ultimate need of infants Nursing Practice Today. 2019; 6(1):46.DOI:10.18502/npt.v6i1.387

Perry R.A, Mallan K.M, Koo J,et al (2015). Food neophobia and its association with diet quality and weight in children aged 24 months: a cross-sectional study. The international journal of behavioural nutrition and physical activity Act. ;12:13. doi:10.1186/s12966-015-0184-6.

Pliner, P.; Hobden, K (1992). Development of a scale to measure the trait of food neophobia in humans. Appetite, 19(2):105-120.

Pliner P. Development of measures of food neophobia in children (1994) Appetite; 23(2): 147-63. 
Samuel F, Ugochukwu C. 2016 Feeding Problems in Infancy and Early Childhood: A case study of selected Primary Health centers in Ibadan North Local Government of Oyo State, Nigeria. The Nigerian Journal of Nutritional Sciences. 37 No. 1

Sanusi R.A, Leshi O.O, Agada U.N., (2016). Mother's knowledge and practice of breastfeeding and complementary feeding in Enugu State, Nigeria. Journal of Research in Nursing and Midwifery (JRNM) (ISSN: 2315-568). 5(1) pp. 021-029.

Sharma, D., \& Kafle, R. (2020) Exclusive Breastfeeding and Complementary Feeding Practices among Children in Slum of Pokhara. Journal of College of Medical Sciences-Nepal, 16(2), 93-98. DOI: https://doi.org/10.3126/jcmsn.v16i2.24797

Shim J.E, Kim J \& Mathai R.A. (2011) Associations of infant feeding practices and picky eating behaviours of preschool children. Journal of American Dietarian Association 111:1363-1368.

Udoh E. E., Amodu O. K., (2016) Complementary feeding practices among mothers and nutritional status of infants in Akpabuyo Area, Cross River State Nigeria. Springer Plus 5:2073.

WHO/UNICEF. (2018) Infant and Young Child Feeding. 